\title{
MODELLING TRAVELLERS' ROUTE SWITCHING BEHAVIOUR IN RESPONSE TO VARIABLE MESSAGE SIGNS USING THE TECHNOLOGY ACCEPTANCE MODEL
}

\author{
El Bachir DIOP, Shengchuan ZHAO*, Shuo SONG, Tran Van DUY \\ School of Transportation and Logistics, Dalian University of Technology, China
}

Received 7 December 2018; revised 10 February 2019; accepted 13 April 2019;

first published online 27 April 2020

\begin{abstract}
Recent studies adopted models of user acceptance of information technology to predict and explain drivers' acceptance of traffic information. Among these frameworks, the most commonly used is the Technology Acceptance Model (TAM). However, TAM is too general and does not consider drivers' response in specific traffic conditions or choice scenarios. This study combines an extended TAM with different choice scenarios displayed by Variable Message Signs (VMS) into a Hybrid Choice Model (HCM). Two models are proposed. The first model takes into account the causal relationships among latent variables based on the following hypotheses: Information Quality (IQ) has a positive effect on Perceived Usefulness (PU) and Perceived Ease of Use (PEOU) which, in turn, have a positive effect on the Behavioural Intention (BI) to use traffic information. In the second model, the four latent variables PU, PEOU, IQ, and BI are directly added to the utility function without any causal relationships. 339 drivers with valid licence were interviewed via Stated Preference (SP) survey and the results show that TAM can explain travellers' response to VMS if the causal relationships among latent variables are taken into account. In addition, all hypothesized relationships are strongly supported. Practical and academic implications are also discussed.
\end{abstract}

Keywords: travel behaviour, route choice model, traffic information, variable message signs, hybrid choice model, technology acceptance model, attitudes, perceptions.

\section{Notations}

ATIS - advanced traveller information systems;

AVE - average variance extracted;

BI - behavioural intention;

CFI - comparative fit index;

CR - composite reliability;

DCM - discrete choice model;

HCM - hybrid choice model;

ICLV - integrated choice and latent variable;

IQ - information quality;

NFI - normed fit index;

PEOU - perceived ease of use;

$\mathrm{PU}$ - perceived usefulness;

$\mathrm{RMB}$ - renminbi, literally from Chinese: "people's currency";

RMSEA - root mean square error of approximation;

$\mathrm{RP}$ - revealed preference;

$\mathrm{SD}$ - standard deviation;

\author{
SP - stated preference; \\ SRMR - standardized root mean square residual; \\ TAM - technology acceptance model; \\ TLI - Tucker-Lewis index; \\ VMS - variable message signs.
}

\section{Introduction}

The Chinese economy has experienced an unprecedented boom in the last 30 years. The economic rise took place after China's adoption of free-market strategies, which allowed the creation of new job opportunities and a fast development of Chinese cities. As a result, many people could afford a car and by 2015 , the number of private cars exceeded 160 million (NBSC 2016). The increase of carownership and a large population in these cities have resulted in many traffic-related problems such as congestion. In order to alleviate traffic congestion, the local authorities adopted ATIS, which provide drivers with pre-trip and

${ }^{*}$ Corresponding author. E-mail: szhao@dlut.edu.cn 
en-route information on their available routes. VMS can provide real-time information and best routing strategies on an urban network and have been widely used in large cities.

Previous research has shown that traffic information can help travellers avoid congestion (Jou et al. 2005) and reduce uncertainty (Levinson 2003). Traffic information can also reduce travel time disutility (Shah et al. 2003; Toledo, Beinhaker 2006) and improve network performance and service quality (Jou et al. 2005). However, traffic information is not effective if travellers do not accept it. Several studies have shown that in many cases the compliance rate to VMS advice is not high enough to ensure a uniform distribution of the traffic (Chatterjee et al. 2002; Gan, Ye 2012; Li et al. 2015; Zhong et al. 2012). In order to improve the compliance rate, several studies investigated the factors affecting travellers' response to VMS. The common objective was to predict and understand travellers' compliance, which could help improve the design and implementation of VMS. In these studies, the main factors affecting travellers' response to VMS could be divided into three categories: information characteristics (accuracy, understandability, timeliness, etc.) (Dutta et al. 2004; Lai, Wong 2000; Ma et al. 2014; Rämä et al. 2004), network characteristics and current network situation (distance, number of signalized intersections, existence of toll road, occurrence of incident, existence of alternate routes etc.) (Bonsall 1992; Chatterjee et al. 2002; Gan, Ye 2012, 2013; Peeta, Ramos 2006; Wardman et al. 1997), and socioeconomic characteristics and trip preferences (age, gender, driving style, income, etc.) (Gan, Ye 2012, 2013; Jou et al. 2005; Li et al. 2015; Zhong et al. 2012).

Most of the aforementioned studies were conducted using DCM with rigid assumptions on the structure of the disturbances, and observed variables such as travel time and cost. Several studies addressed this issue with more flexible models that also incorporate travellers' attitudes and perceptions as latent variables into the traditional DCM: HCM. HCM help better explain population heterogeneity and have been adopted to investigate route choice behaviour (Bekhor, Albert 2014; Prato et al. 2012), especially travellers' route switching behaviour in response to travel information (Feng, Kuo 2007; Kattan et al. 2010; Majumder et al. 2013).

Recently, several research efforts in the transportation arena have adopted psychometric methods of user acceptance of information technology to better understand travellers' response to road guidance systems - see Isa et al. (2015) for review. These methods focused on the useroriented design of ATIS and have demonstrated that attitudes and perceptions are major factors affecting drivers' acceptance of traffic information. Among these methods, the TAM is the most widely used.

TAM was developed by Davis (1989) to predict user acceptance of information technology. The model assumes that an individual's actual system use is predicted by his/ her intention to adopt the given system. The intention to use is determined by the individual's attitude towards using the system. Attitude is defined as the individual's positive or negative feelings towards performing a behaviour (Fishbein, Ajzen 1975). Davis further posits that attitude is determined by two salient beliefs about the given technology: PU and PEOU. PU is the extent to which an individual believes that using a particular technology will improve his/her job performance (Davis 1989). PEOU is the extent to which an individual believes that using a particular technology is free of effort (Davis 1989). Later on, attitude was found to only partially mediate the effects of PU and PEOU on BI and was excluded from the final parsimonious TAM (Davis, Venkatesh 1996; Venkatesh et al. 2003) (Figure 1). TAM is a robust and simple framework and has recently been adopted to predict and explain road users' acceptance of safety warning systems (Larue et al. 2015; Roberts et al. 2012), ATIS for route and departure time choice (Lin et al. 2014; Xu et al. 2010), and other invehicle and multimedia devices (Chen, C.-F., Chen, P.-C. 2011; Chen, H.-H., Chen, S.-C. 2009).

However, TAM is too general and does not investigate traveller's response to ATIS in a specific traffic condition. For example, previous research has demonstrated that travellers' response to ATIS is not only affected by their attitudes and perceptions but also by current traffic conditions such as occurrence of congestion, travel time, delay, number of signalized intersections, etc. In summary, the major drawback of the traditional DCM is its rigidity and the non-inclusion of psychometric attributes such as attitudes and perceptions while TAM is limited by its generality and inability to predict travellers' response in specific traffic situations. Thus, combining the two methodologies could help exploit the advantages and overcome the weaknesses of each model. This could be done by developing an ICLV model in which TAM, enriched with IQ, is incorporated into the traditional DCM. Furthermore, one of the major drawbacks in many HCM studies is the lack of theoretical and empirical support on the choice of latent variables (Mariel, Meyerhoff 2016). Also, although a few studies recognized the need to investigate the hierarchical relationships among latent variables for more realistic models (Abou-Zeid, Ben-Akiva 2011; Kamargianni et al. 2014; Paulssen et al. 2014), many others did not (Bekhor, Albert 2014; Cantillo et al. 2015; Kim et al. 2014; Prato et al. 2012; Vredin Johansson et al. 2006; Yáñez et al. 2010). To the best of the authors' knowledge, the few studies that investigated the causal relationships mainly fo-

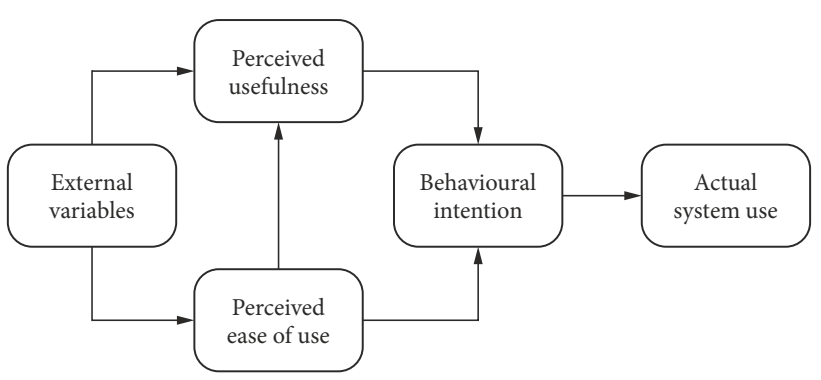

Figure 1. Parsimonious TAM (Davis, Venkatesh 1996) 
cused on mode choice behaviour, not route choice. In the context of route choice behaviour, Feng and Kuo (2007) used a structural equation model to investigate the causal relationships among latent variables, but did not incorporate these relationships into their HCM. TAM has already been empirically validated in previous studies and, unlike many previous studies, the model will also take into account the hierarchical relationships among the different latent variables (IQ, PU, PEOU and $\mathrm{BI}$ ). In order to prove the need to consider the hierarchical relationships among constructs, we also developed another model in which the four latent constructs are simultaneously added to the utility function (without considering the causal relationships among them). SP data with repeated observations from 339 respondents in Dalian City (China) were used to test the models.

The remainder of this paper is organized as follows. Section 1 formulates hypotheses on the causal relationships among the latent constructs. Sections 2 and 3 describe the data collection and modelling methodologies, respectively. Section 4 describes the results. The last section concludes this study with implications, limitations and directions for future research.

\section{Research hypotheses}

This section formulates hypotheses on the causal relationships among the constructs as well as their effect on travellers' response to specific information provided by VMS.

\subsection{Traditional TAM}

Based on the parsimonious TAM presented in the previous Section and results from previous studies on user acceptance of road guidance systems (Larue et al. 2015; Park et al. 2015; Roberts et al. 2012; Xu et al. 2010), we hypothesize:

- H1: PU has a positive effect on BI;

- H2: PEOU has a positive effect on BI;

- H3: PEOU has a positive effect on PU.

\subsection{Augmenting TAM with IQ}

Although TAM is a robust model for explaining user acceptance of information technology, previous research has shown that the model is more accurate if enriched with external variables that offer a better understanding of PU and PEOU (Venkatesh 2000; Venkatesh, Davis 2000; Venkatesh et al. 2003). In the context of this study, we decided to extend TAM with IQ because of its tremendous effect on travellers' acceptance of ATIS. IQ is characterized by accuracy, timeliness, and completeness (Lin et al. 2014). Studies in the driving assistance domain have shown that a VMS that provides accurate, timely and complete information is easier to use (ease of use) and is more likely to help travellers improve their travel benefits (usefulness) (Chatterjee et al. 2002; Ma et al. 2014; Peeta, Ramos 2006). Thus, we can expect IQ to have a positive effect on PU and
PEOU. These relationships are also supported by previous studies (Ahn et al. 2007; Lin et al. 2014). Therefore, we propose:

- H4: IQ has a positive effect on PU;

- H5: IQ has a positive effect on PEOU.

\subsection{Acceptance and route switching behaviour}

TAM uses BI to model user acceptance of information technology. Intention was defined as the individual's perceived probability that he/she would perform a behaviour and was assumed to predict actual system use (Davis 1989; Davis et al. 1989). In the context of this study, intention would predict traveller's compliance with VMS given the information displayed and the current network conditions. Thus, we can expect that travellers who intend to use traffic information would be more likely to divert in response to VMS information. Therefore, we hypothesize:

- H6: BI has a positive effect on route diversion.

Figure 2 depicts the causal relationships proposed in this section.

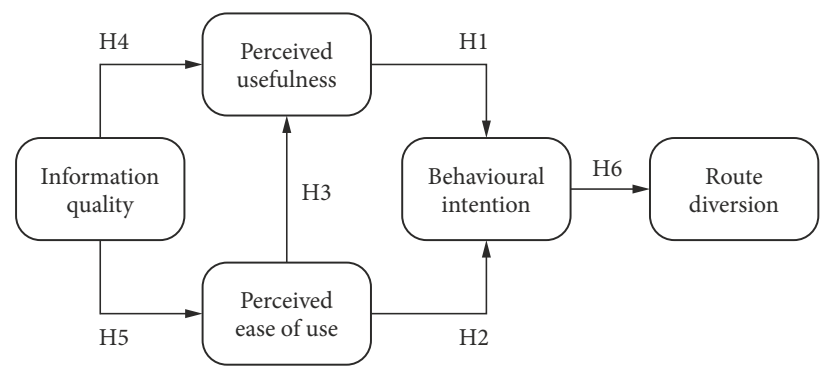

Figure 2. Causal relationships among variables

\section{Data collection}

Two methods are usually adopted to collect data on travellers' response to ATIS: SP and RP methods. SP methods analyse the behaviour in hypothetical scenarios designed by the analyst. RP methods examine the behaviour in reallife situations. RP data are more realistic as the respondent does not need to imagine the scenario before making a decision. As a result, the use of RP data can help avoid the biases associated with SP survey such as justification bias (Koutsopoulos et al. 1993). However, RP surveys are expensive and can only be used to investigate travellers' response to the VMS displayed during the survey period, which limits the analyst's control over the values of the attributes. Thus, we adopted SP method.

The survey consists of three parts: individual characteristics, attitudinal indicators and SP scenarios.

\subsection{Individual characteristics}

Participants with valid driver licence were interviewed in the parking areas near the shopping malls located in the vicinity of the study area. They provided basic information such as their age, gender and route choice style. 500 questionnaires were distributed and 339 valid responses 
were collected (response rate 67.8\%). Table 1 shows a summary of the individual characteristics collected. Of the 339 respondents, $63.13 \%$ were male, $36.87 \%$ female. According to the Dalian Police Department, the distribution of gender among the driving population is: male: $66.39 \%$; female: $33.62 \%$. This distribution is similar to the sample used in this study. The majority of the respondents were young (62.54\%). People aged between 31 and 50 years represented $33.33 \%$ and people over 50 years old counted for $4.13 \%$ of the respondents. Regarding driving experience, $23.01 \%$ had been driving for less than one year. $47.49 \%$ had driving years between 1 and 5 years, 29.5\% more than 5 years. Most of Chinese people started to learn how to drive from 2005, and this population group has gradually increased, therefore most of the driving population is less experienced. Furthermore, most people from earlier generations could not afford a car and did not bother learning how to drive. This explains why the driving population is relatively young. Of the 339 respondents, $62.54 \%$ had a monthly income lower than $5000 \mathrm{RMB}, 28.32 \%$ had income between 5000 and $10000 \mathrm{RMB}$. The remaining 9.14\% had an income over $10000 \mathrm{RMB}$. We did not have detailed data on the distribution of income. However, China is still a developing country with a large population; the majority of the population in cities such as Dalian has low income. This is not the case in mega cities such as Beijing, Shanghai, Guangzhou and Shenzhen, which are more developed. The distribution of route choice style is as follows: $3.83 \%$ had static route choice style, $15.04 \%$ used their experience, $17.99 \%$ used traffic information and $63.13 \%$ combined traffic information with their experience.

Table 1. Socioeconomic and trip characteristics

\begin{tabular}{|c|c|c|}
\hline Attributes & $\begin{array}{c}\text { Frequency } \\
(N=339)\end{array}$ & $\begin{array}{c}\text { Percentage } \\
{[\%]}\end{array}$ \\
\hline \multicolumn{3}{|c|}{ Gender } \\
\hline male & 214 & 63.13 \\
\hline female & 125 & 36.87 \\
\hline \multicolumn{3}{|c|}{ Age group } \\
\hline $18 \ldots 30$ years old & 212 & 62.54 \\
\hline $31 \ldots 50$ years old & 113 & 33.33 \\
\hline over 50 years old & 14 & 4.13 \\
\hline \multicolumn{3}{|c|}{ Monthly income $(1 \mathrm{RMB} \approx 0.15$ USD $)$} \\
\hline less than $5000 \mathrm{RMB}$ & 212 & 62.54 \\
\hline $5000 \ldots 10000 \mathrm{RMB}$ & 96 & 28.32 \\
\hline more than $10000 \mathrm{RMB}$ & 31 & 9.14 \\
\hline \multicolumn{3}{|c|}{ Driving years } \\
\hline less than 1 year & 78 & 23.01 \\
\hline $1 \ldots 5$ years & 161 & 47.49 \\
\hline more than 5 years & 100 & 29.5 \\
\hline \multicolumn{3}{|c|}{ Route choice style } \\
\hline static & 13 & 3.83 \\
\hline information-based & 61 & 17.99 \\
\hline experience-based & 51 & 15.04 \\
\hline information-experience-based & 214 & 63.13 \\
\hline
\end{tabular}

\subsection{Measurement scales}

The selection of measurement items was based on a strong theoretical and empirical background and all indicators were validated in previous research (Ayeh et al. 2013; Chen, C.-F., Chen, P.-C. 2011; Davis 1989; Davis et al. 1989; Lin et al. 2014). After a careful review of the literature on traffic psychology, users' acceptance of information technology and travellers' response to ATIS, a focus group consisting of ATIS experts and college professors selected 15 items that might be relevant in this study. With the help of two language experts, the questionnaire was translated into Chinese language. We then conducted a pilot survey to check the validity and reliability of the questionnaire. 92 graduate students and faculty members were interviewed and the results helped refine the wording and eliminate the least relevant items. The respondents were asked to state their responses based on their experience with VMS. Since the whole urban network in Dalian was equipped with VMS, the respondents would not have a hard time stating their perceptions. Finally, 14 items were selected for the final survey (Table 2).

Table 2. List of measurement items

\begin{tabular}{|c|c|c|}
\hline Construct & Indicator & Wording \\
\hline \multirow{4}{*}{$\mathrm{PU}$} & PU1 & $\begin{array}{l}\text { Using VMS information helps me in } \\
\text { avoiding congestion }\end{array}$ \\
\hline & PU2 & $\begin{array}{l}\text { VMS information helps me in } \\
\text { arriving to my destination on time }\end{array}$ \\
\hline & PU3 & $\begin{array}{l}\text { VMS information helps me make } \\
\text { better routing and departure time } \\
\text { choices }\end{array}$ \\
\hline & PU4 & $\begin{array}{l}\text { Overall, I find VMS information } \\
\text { useful }\end{array}$ \\
\hline \multirow{4}{*}{ PEOU } & PEOU1 & $\begin{array}{l}\text { Using VMS information does not } \\
\text { require a lot of mental effort }\end{array}$ \\
\hline & PEOU2 & $\begin{array}{l}\text { It is easy to learn how to use VMS } \\
\text { information }\end{array}$ \\
\hline & PEOU3 & $\begin{array}{l}\text { VMS information is easy to } \\
\text { understand }\end{array}$ \\
\hline & PEOU4 & $\begin{array}{l}\text { Overall, I find VMS information } \\
\text { easy to use }\end{array}$ \\
\hline \multirow{3}{*}{ IQ } & IQ1 & $\begin{array}{l}\text { VMS provides accurate traveller } \\
\text { information }\end{array}$ \\
\hline & IQ2 & $\begin{array}{l}\text { VMS provides complete traveller } \\
\text { information }\end{array}$ \\
\hline & IQ3 & $\begin{array}{l}\text { VMS provides timely traveller } \\
\text { information }\end{array}$ \\
\hline \multirow{3}{*}{ BI } & BI1 & $\begin{array}{l}\text { I would consider using VMS } \\
\text { information as long as it is available }\end{array}$ \\
\hline & BI2 & $\begin{array}{l}\text { I will very likely use VMS } \\
\text { information if it is available }\end{array}$ \\
\hline & BI3 & $\begin{array}{l}\text { I would recommend others to use } \\
\text { VMS information for their trips }\end{array}$ \\
\hline
\end{tabular}




\subsection{Choice scenarios}

The SP survey investigates commuters' trip between their home (near Dalian University of Technology) and their workplace in the city centre (Zhongshan Square). As shown in Figure 3, the study network consists of two main routes: an expressway (in black) and a local street (in blue). The local street is longer, has a lower speed limit and is equipped with signalized intersections. For these reasons, most commuters prefer the expressway for their trip. However, in case of incident (accident or congestion during peak hours), the VMS can inform travellers and redirect them to the local street. The VMS is located around $1 \mathrm{~km}$ upstream the detour point and provides real-time information on the expressway and the local street. Based on the information received and their attitudes and perceptions, travellers will decide whether to divert or not.

The local street is divided into four sections and the expressway consists of two sections (Figure 4). The distance corresponding to each road section is given in Table 3. The conditions on each part of the two routes are provided

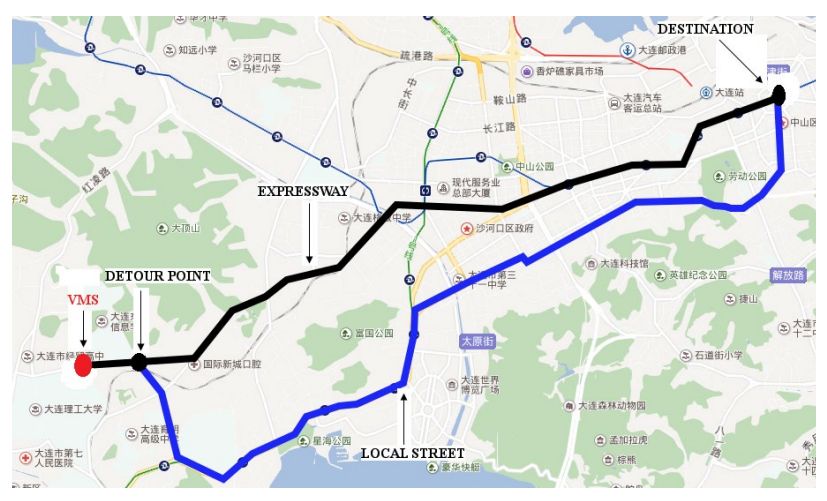

Figure 3. Study network (source: https://map.baidu.com) using the following colour code: green (free flowing), yellow (light congestion) and red (congestion). The speed corresponding to each colour is given in Table 4 and is consistent with values used in China (Zhong et al. 2012). In case of congestion, the expressway is slower; therefore the speed on the two parts of the expressway takes the following levels: yellow and red. For simplicity, only the speed on the main parts of the local street ( $a 2$ and $a 3$ ) varies. The speed on $a 1$ and $a 4$ is fixed to green. Since in our experiment the local street is less congested, the speed on $a 2$ and $a 3$ is assumed to be faster and takes the following two levels: yellow and green. In addition to the speed, the VMS may provide guidance on the best route. Thus, the type of information takes two levels: with guidance (1) and without guidance (0). Finally, the number of signalized intersections on the local street takes two levels: 10 and 20. In this study, we also wanted to investigate the effect of road characteristics on travellers' choice. That is why the number of signalized intersections varies. Thus, we have six attributes: speed on $e 1, e 2, a 2$, and $a 3$, information type and number of signalized intersections on the local street (Table 5). Since each of the six attributes has two levels, we obtain a full factorial design of 64 combinations $\left(2^{6}=64\right)$. Given the large number of combinations and with the intention to make the survey as convenient as possible for the respondents, we transformed our design into a well balanced orthogonal design with 16 combinations. Still keeping in mind our desire to make the experiment bearable to the respondents, the obtained design was split into 4 blocks of 4 SP combinations. Thus, in addition to individual characteristics and attitudinal indicators, each respondent only had to choose his/her route in 4 scenarios. That way they could focus on each scenario and give a reliable response. Figure 5 shows examples of SP scenarios shown to the respondents.

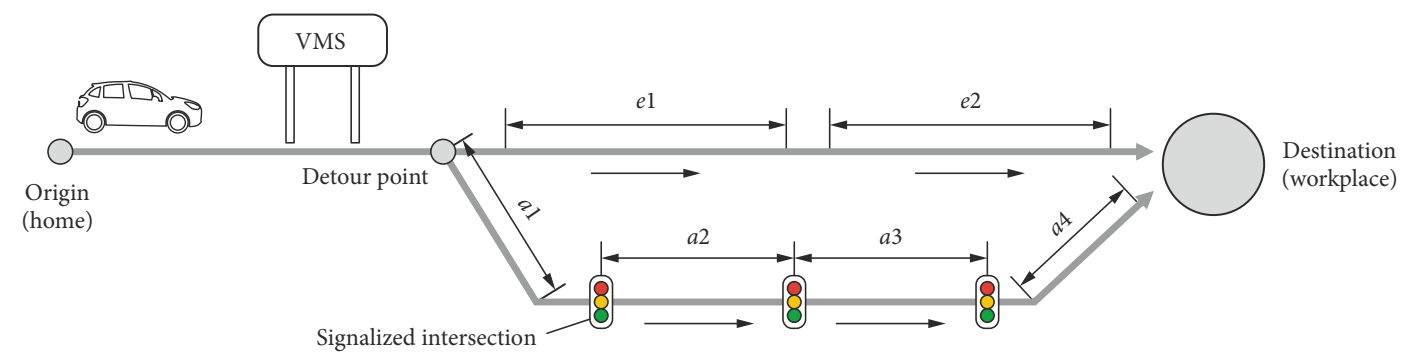

Figure 4. Network layout

Table 3. Distance corresponding to road sections

\begin{tabular}{|l|c|c|c|c|c|c|}
\hline Road section: & $a 1$ & $a 2$ & $a 3$ & $a 4$ & $e 1$ & $e 2$ \\
\hline Distance $[\mathrm{km}]:$ & 2.5 & 4.7 & 4.1 & 2.4 & 6.0 & 4.5 \\
\hline
\end{tabular}

Table 4. Road colours and their corresponding average speed

\begin{tabular}{|l|c|c|c|}
\hline Colour: & green & yellow & red \\
\hline Speed $[\mathrm{m} / \mathrm{s}]:$ & 8.1278 & 4.9222 & 2.0694 \\
\hline
\end{tabular}

Table 5. Attributes and their levels

\begin{tabular}{|l|l|}
\hline \multicolumn{1}{|c|}{ Attribute } & \multicolumn{1}{c|}{ Level } \\
\hline VMS colour on $a 2$ & yellow, green \\
\hline VMS colour on $a 3$ & yellow, green \\
\hline VMS colour on $e 1$ & red, yellow \\
\hline VMS colour on $e 2$ & red, yellow \\
\hline Provision of guidance & $\begin{array}{l}\text { guidance (1), } \\
\text { no guidance }(0)\end{array}$ \\
\hline Number of signalized intersections & 10,20 \\
\hline
\end{tabular}


a)

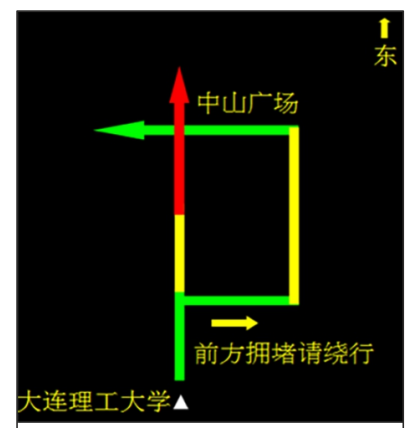

Number of signalized intersections on local street: 20

Given the current scenario, which route would you choose?

Expressway $\square$ Local street

Figure 5. Examples of SP scenarios: a - information with guidance; $b$ - information without guidance

\section{Methodology}

\subsection{Model formulation}

A HCM consists of two models: a latent variable model and a DCM. Each model can further be divided into a structural sub-model and a measurement sub-model. Figure 6 depicts the HCM framework used in this study. The rectangles correspond to observed variables, the spheres represent latent variables, the solid arrows indicate structural equations, and the dashed arrows represent measurement equations.

\subsubsection{The structural sub-models}

The structural equation of the latent variable model defines the endogenous latent variables as a function of exogenous and/or endogenous latent variables and individual characteristics, and the exogenous latent variables as a function of individual characteristics. The structural equation of the choice model describes the utilities as a function of latent variables and alternative attributes.

For the structural equation of the exogenous latent variables $X_{n}^{*}$, we need the distribution of $X_{n}^{*}$ given the individual characteristics $h_{1}\left(X_{n}^{*} \mid X_{n} ; \alpha, \Sigma_{\mathrm{v}}\right)$ :

$$
\begin{aligned}
& X_{n}^{*}=\alpha \cdot X_{n}+\mathrm{v}_{n}, \\
& \mathrm{v}_{n} \sim D\left(0, \Sigma_{\mathrm{v}}\right),
\end{aligned}
$$

where: $X_{n}^{*}$ is a vector of exogenous latent variables; $X_{n}$ is a vector of explanatory variables (socioeconomic and trip characteristics); $\alpha$ is a matrix of unknown parameters; $v_{n}$ is a vector of random disturbance terms following a distribution $D$ with covariance matrix $\Sigma_{v} ; h_{1}$ is the density function of the exogenous latent variables.

For the structural equation of the endogenous latent variables $E_{n}^{*}$, we need the distribution of $E_{n}^{*}$ given the exogenous and/or endogenous latent variables and individual characteristics $h_{2}\left(E_{n}^{*} \mid X_{n}, X_{n}^{*}, E_{n}^{*} ; \beta, \Sigma_{\omega}\right)$ :

$$
\begin{aligned}
& E_{n}^{*}=\beta_{1} \cdot X_{n}+\beta_{2} \cdot X_{n}^{*}+\beta_{3} \cdot E_{n}^{*}+\omega_{n}, \\
& \omega_{n} \sim D\left(0, \Sigma_{\omega}\right),
\end{aligned}
$$

where: $E_{n}^{*}$ is a vector of endogenous latent variables; $X_{n}$ is a vector of explanatory variable (socioeconomic and trip characteristics); $X_{n}^{*}$ is a vector of exogenous latent variables;

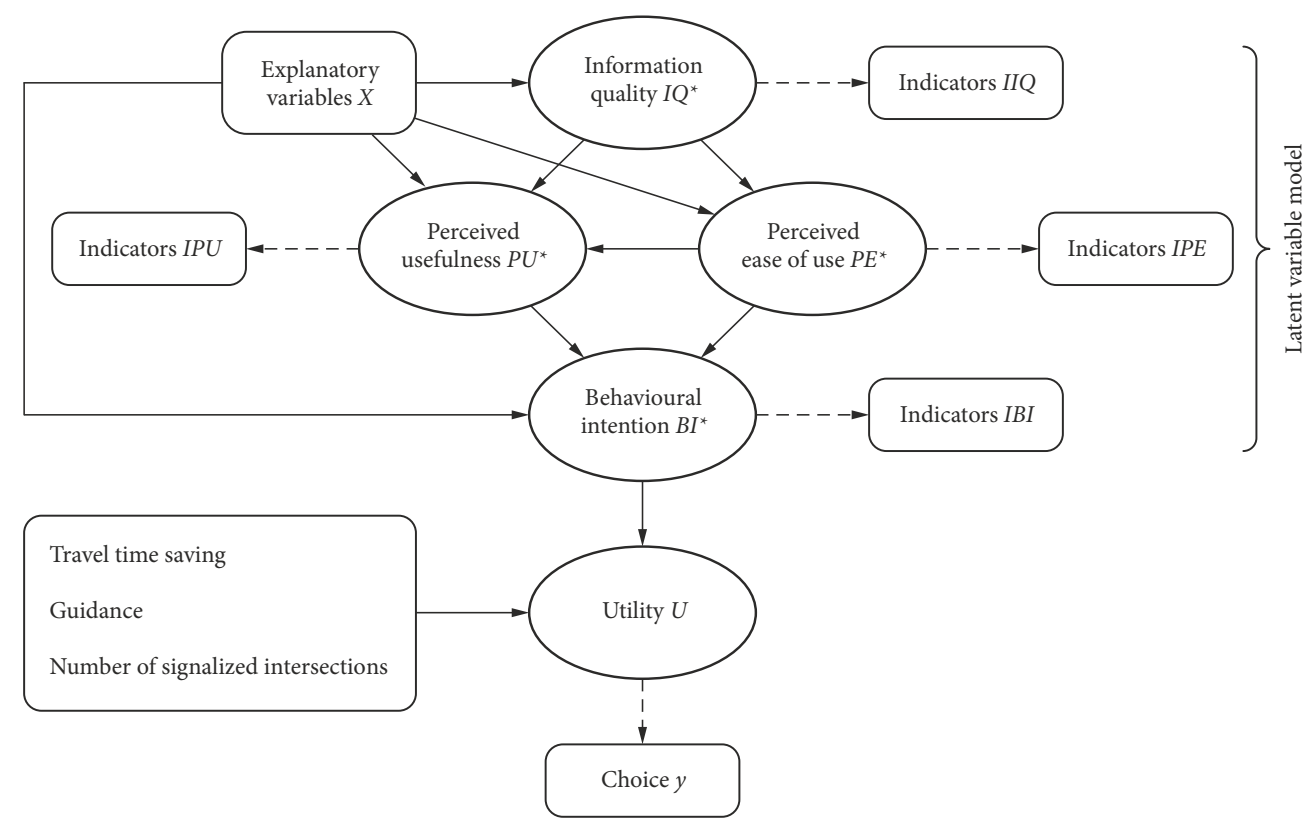

Figure 6. Proposed HCM 
$\beta, \beta_{i}$ are matrices of unknown parameters; $\omega_{n}$ is a vector of random disturbance terms following a distribution $D$ with covariance matrix $\Sigma_{\omega} ; h_{2}$ is the density function of the endogenous latent variables.

For the structural equation of the choice model, we need the distribution of the utilities $f\left(U_{n} \mid Z_{n}, E_{n}^{*} ; \theta, \Sigma_{\varepsilon}\right)$ :

$$
\begin{aligned}
& U_{n}=Z_{n} \cdot \theta_{1}+E_{n}^{*} \cdot \theta_{2}+\sigma_{n}+\varepsilon_{n}, \\
& \varepsilon_{n} \sim D\left(0, \Sigma_{\varepsilon}\right),
\end{aligned}
$$

where: $U_{n}$ is a vector of utilities; $Z_{n}$ is a vector of route choice attributes (travel time, number of signals, etc.); $E_{n}^{*}$ is a vector of endogenous latent variable; $\theta, \theta_{i}$ are vectors of unknown parameters; $\varepsilon_{n}$ is a vector of random disturbance terms following a distribution $D$ with covariance matrix $\Sigma_{\varepsilon} ; f$ is the distribution function of the utilities; $\sigma_{n}$ is added to capture serial correlation due to repeated observations in the SP survey.

\subsubsection{The measurement sub-models}

The measurement sub-model of the latent variable model relates the latent variables to indicators, which can be obtained from survey questions. For the measurement equations of the exogenous latent variables, we need the distribution of the latent indicators $I X_{n}$ given $X_{n}^{*}$, $d_{1}\left(I X_{n} \mid X_{n}^{*} ; \gamma, \Sigma_{\xi}\right)$ :

$$
\begin{aligned}
& I X_{n}=\gamma \cdot X_{n}^{*}+\xi_{n}, \\
& \xi_{n} \sim D\left(0, \Sigma_{\xi}\right),
\end{aligned}
$$

where: $I X_{n}$ is a vector of indicators of latent variables; $X_{n}^{*}$ is a vector of exogenous latent variables; $\gamma$ is a vector of unknown parameter; $\xi_{n}$ is a vector of random disturbance terms following a distribution $D$ with covariance matrix $\Sigma_{\xi} ; d_{1}$ is the density function of the indicators of exogenous latent variables.

For the measurement equations of the endogenous latent variables, we need the distribution of latent indicators $I E_{n}$ given $E_{n}^{*}, d_{2}\left(I E_{n} \mid E_{n}^{*} ; \lambda, \Sigma_{\zeta}\right)$ :

$$
\begin{aligned}
& I E_{n}=\lambda \cdot E_{n}^{*}+\zeta_{n}, \\
& \zeta_{n} \sim D\left(0, \Sigma_{\zeta}\right),
\end{aligned}
$$

where: $I E_{n}$ is a vector of indicators of latent variables; $E_{n}^{*}$ is a vector of endogenous latent variables; $\lambda$ is a vector of unknown parameters; $\zeta_{n}$ is a vector of random disturbance terms following a distribution $D$ with covariance matrix $\Sigma_{\xi} ; d_{2}$ is the density function of the indicators of endogenous latent variables.

The measurement sub-model of the choice model links the latent utility to choice indicators obtained from survey questions. An individual $n$ is assumed to choose the alternative $i$ that maximizes his/her utility; therefore the measurement equation of the choice model is written as follows:

$$
y_{\text {in }}=\left\{\begin{array}{l}
1, \text { if } U_{\text {in }} \geq U_{j n}, \quad \forall j \neq i \\
0, \text { otherwise, }
\end{array}\right.
$$

where: $y_{i n}$ is the indicator corresponding to alternative $i$; $U_{\text {in }}$ is the utility associated with alternative $i$ for individual $n ; U_{j n}$ is the utility associated with the other alternatives.

\subsubsection{Likelihood function}

Maximum simulated likelihood technique was used to estimate the model. The likelihood of a given observation is the joint probability of observing the choice and the indicator for the latent variable. Since a latent variable is only known to its distributions, we integrate the probability over the distribution of the latent variables. Assuming that all error terms are independent, we can write the likelihood function as follows:

$$
\begin{aligned}
& P\left(y_{n}, I X_{n}, I E_{n} \mid Z_{n}, X_{n}, \vartheta\right)= \\
& \iint_{X_{n}^{*} E_{n}^{*}} P\left(y_{n} \mid Z_{n}, E_{n}^{*} ; \theta, \Sigma_{\varepsilon}\right) \cdot d_{1}\left(I X_{n} \mid X_{n}^{*} ; \gamma, \Sigma_{\xi}\right) \times \\
& d_{2}\left(I E_{n} \mid E_{n}^{*} ; \lambda, \Sigma_{\zeta}\right) \cdot h_{1}\left(X_{n}^{*} \mid X_{n} ; \alpha, \Sigma_{\nu}\right) \times \\
& h_{2}\left(E_{n}^{*} \mid E_{n}^{*}, X_{n}^{*}, X_{n} ; \beta, \Sigma_{\omega}\right) \mathrm{d} E_{n}^{*} \mathrm{~d} X_{n}^{*},
\end{aligned}
$$

where: $P$ is the choice probability; $y_{n}$ is the choice indicator; $\vartheta=\left\{\theta, \Sigma_{\varepsilon}, \gamma, \Sigma_{\xi}, \lambda, \Sigma_{\zeta}, \alpha, \Sigma_{v}, \beta, \Sigma_{\omega}\right\}$ is the full set of parameters to be estimated.

A more detailed explanation of the HCM can be found in Ben-Akiva et al. (1999).

\subsection{Model specification}

Several specifications were tested before finding our optimal model. First, we developed a model that incorporates the individual characteristics into the latent variable and choice models (utility function). However, the individual characteristics had little direct effect on the choice model; their effect is absorbed by the latent variables through the structural equations. Thus, we removed them from the utility of the choice model. We also developed a model that takes into account the interactions among the latent variables and choice attributes (travel time, guidance, etc.) as in Bekhor and Albert (2014). However, the interactions had no significant effect. The model shown here only considers the effect of the individual characteristics on the latent variables and has no interaction among latent variables and choice attributes. In addition to the model detailed in this section, we also developed a traditional HCM in which all latent variables were simultaneously incorporated into the choice model without any causal relationships. This model is used to demonstrate the need to consider the causal relationships among latent variables and its results are also shown in the next section.

The structural equations of the latent variable model are defined as follows:

$$
\begin{aligned}
& I Q_{n}=\alpha_{I Q}+\alpha_{1,1} \cdot \text { Male }_{n}+ \\
& \alpha_{1,2} \cdot \text { Age31_50 } 0_{n}+\alpha_{1,3} \cdot{\text { Age } 50_{n}^{+}+} \\
& \alpha_{1,4} \cdot \text { Inc5_10 } k_{n}+\alpha_{1,5} \cdot I_{n c 10 k_{n}^{+}+}
\end{aligned}
$$




$$
\begin{aligned}
& \alpha_{1,6} \cdot \operatorname{Exp} 1_{-} 5_{n}+\alpha_{1,7} \cdot \operatorname{Exp} 5_{n}^{+}+ \\
& \alpha_{1,8} \cdot \text { Info_based }_{n}+\alpha_{1,9} \cdot \text { Exp_based }_{n}+ \\
& \alpha_{1,10} \cdot \text { Info_Exp_based }_{n}+\mathrm{v}_{1, n} \text {; } \\
& \text { PEOU }_{n}=\beta_{P E O U}+\beta_{1,1} \cdot \text { Male }_{n}+ \\
& \beta_{1,2} \cdot \text { Age31_50 }{ }_{n}+\beta_{1,3} \cdot \text { Age } 50_{n}^{+}+ \\
& \beta_{1,4} \cdot \text { Inc5_10 } k_{n}+\beta_{1,5} \cdot \operatorname{Inc10k_{n}^{+}+} \\
& \beta_{1,6} \cdot \operatorname{Exp} 1_{-} 5_{n}+\beta_{1,7} \cdot \operatorname{Exp} 5_{n}^{+}+ \\
& \beta_{1,8} \cdot \text { Info_based }_{n}+\beta_{1,9} \cdot \text { Exp_based }_{n}+ \\
& \beta_{1,10} \cdot \text { Info_Exp_based }_{n}+ \\
& \beta_{1,11} \cdot I Q_{n}+\omega_{1, n} ; \\
& P U_{n}=\beta_{P U}+\beta_{2,1} \cdot \text { Male }_{n}+ \\
& \beta_{2,2} \cdot \text { Age31_50 } 0_{n}+\beta_{2,3} \cdot \text { Age } 50_{n}^{+}+ \\
& \beta_{2,4} \cdot \operatorname{Inc5} \_10 k_{n}+\beta_{2,5} \cdot \operatorname{Inc10k_{n}^{+}+} \\
& \beta_{2,6} \cdot \operatorname{Exp} 1_{-} 5_{n}+\beta_{2,7} \cdot \operatorname{Exp} 5_{n}^{+}+ \\
& \beta_{2,8} \cdot \text { Info_based }_{n}+\beta_{2,9} \cdot \text { Exp_based }_{n}+ \\
& \beta_{2,10} \cdot \text { Info_Exp_based }_{n}+ \\
& \beta_{2,11} \cdot I Q_{n}+\beta_{2,12} \cdot \text { PEOU }_{n}+\omega_{2, n} ; \\
& B I_{n}=\beta_{B I}+\beta_{3,1} \cdot \text { Male }_{n}+ \\
& \beta_{3,2} \cdot \text { Age31_50 } 0_{n}+\beta_{3,3} \cdot{\text { Age } 50_{n}^{+}+}^{+} \\
& \beta_{3,4} \cdot \operatorname{Inc5}{ }_{-} 10 k_{n}+\beta_{3,5} \cdot \operatorname{Inc} 10 k_{n}^{+}+ \\
& \beta_{3,6} \cdot \operatorname{Exp} 1_{-} 5_{n}+\beta_{3,7} \cdot \operatorname{Exp} 5_{n}^{+}+ \\
& \beta_{3,8} \cdot \text { Info_based }_{n}+\beta_{3,9} \cdot \text { Exp_based }_{n}+ \\
& \beta_{3,10} \cdot \text { Info_Exp_based }+ \\
& \beta_{3,11} \cdot P E O U_{n}+\beta_{3,12} \cdot P U_{n}+\omega_{3, n} \text {, }
\end{aligned}
$$

where: Male $_{n}$ is a dummy variable that represents the gender (1 for male, 0 for female); Age $31_{-} 50_{n}$, Age $50_{n}^{+}$represent the age of the respondent (between $31 \ldots 50$ and more than 50 years old, respectively), the sub-group " $18 \ldots . .30$ years old" is the reference category for age; Inc $5 \_10 k_{n}$, Inc $10 k_{n}^{+}$represent the income of the respondent (between $5000 \ldots 10000 \mathrm{RMB}$ and more than $10000 \mathrm{RMB}$, respectively), the sub-group "less than $5000 \mathrm{RMB}$ " is the reference category for income; $\operatorname{Exp} 1_{-} 5_{n}, \operatorname{Exp} 5_{n}^{+}$represent the years of driving experience of the respondent (between 1...5 years and more than 5 years, respectively), the sub-group "less than 1 year" is the reference category for driving experience; Info_based ${ }_{n}$, Exp_based ${ }_{n}$, Info_Exp_based ${ }_{n}$ represent the route choice style of the respondent (information-based, experience-based and information-experience-based, respectively), the sub-group "static" is the reference category for route choice style; $I Q_{n}, P E O U_{n}, P U_{n}$, $B I_{n}$ are the latent variables corresponding to IQ, PEOU, $\mathrm{PU}$ and $\mathrm{BI}$, respectively.

The measurement equations of the latent variable model relate the latent variables to choice indicators $I$. As an example, the measurement equation for PEOU is defined as follows:

$$
I_{P E O U, n}=\lambda_{0, P E O U}+\lambda_{P E O U} \cdot P E O U_{n}+\zeta_{P E O U, n},
$$

where: $I_{P E O U, n}$ is a vector of latent indicators; $\lambda_{0, P E O U}$, $\lambda_{P E O U}$ are vectors of regression parameters; $P E O U_{n}$ is the latent variable corresponding to PEOU; $\zeta_{P E O U, n}$ is a vector of error terms. In this study, all indicators are considered as categorical variables. Thus, the measurements equations are estimated using ordered probit models (Daly et al. 2012).

The structural equations of the choice model are defined as follows:

$$
\begin{aligned}
& U_{E X P, n}=A S C_{E X P}+\theta_{-} T T S A V \cdot T T_{-} S A V+ \\
& \theta_{-} G U I D \cdot G U I D+\varepsilon_{E X P, n} ; \\
& U_{L O C, n}=\theta^{\sim} S T O P \cdot N B \quad S T O P+ \\
& \theta \quad I N T \cdot I N T_{n}+\sigma_{n}+\varepsilon_{L O C, n},
\end{aligned}
$$

where: $U_{E X P, n}$ is the utility of the expressway; $U_{L O C, n}$ is the utility of the local street; - is the alternativespecific constant associated with expressway; TT_SAV is the time saved through diverting and is equal to the difference between travel time on expressway and travel time on local street; GUID is a dummy variable that equals 1 if the information is provided with guidance, 0 otherwise; NB_STOP is the number of signalized intersections on the local street; $I N T_{n}$ is the latent variable representing the respondent's intention (BI) to use traffic information provided by VMS; $\theta \_T T S A V, \theta \_G U I D, \theta \_S T O P, \theta \_I N T$ are unknown parameters; $\sigma_{n}$ is the error term which captures panel correlation; $\varepsilon_{E X P, n}$ and $\varepsilon_{L O C, n}$ are error terms.

The travel times are obtained by using the speed (Table 4) and distance on each road section (Table 3 ) as follows:

$$
T=\sum_{i=1}^{m} \frac{d_{i}}{s_{i}},
$$

where: $T$ is the total travel time on a given route; $m$ is the number of road sections ( 2 for the expressway, 4 for the local street); $d_{i}$ is the distance on road section $i ; s_{i}$ is the speed on road section $i$.

The HCM is simultaneously estimated using PythonBiogeme (https://biogeme.epfl.ch) (Bierlaire 2003) with 1000 Halton draws.

\section{Results}

Before incorporating the latent variables into the DCM, we need to verify the reliability and validity of the measurement model. In order to do so, we built a CFA with the four constructs PU, PEOU, IQ and BI. In the HCM, the latent variable and choice model are estimated simultaneously. Thus, the CFA is only used here to test the validity and reliability of the items.

\subsection{Results of the confirmatory factor analysis}

For internal consistency, the CR must be larger than 0.6 (Bagozzi, Yi 1988). Table 6 shows that all latent constructs meet the requirements for internal consistency. Conver- 
Table 6. Results of confirmatory factor analysis

\begin{tabular}{|c|c|c|c|c|c|c|c|}
\hline Construct & Indicator & Mean & SD & AVE & $\lambda$ & $p$-value & $\mathrm{CR}$ \\
\hline \multirow{4}{*}{ PU } & PU1 & 4.525 & 0.597 & \multirow{4}{*}{0.563} & 0.649 & $<0.001$ & \multirow{4}{*}{0.836} \\
\hline & PU2 & 4.428 & 0.659 & & 0.768 & $<0.001$ & \\
\hline & PU3 & 4.478 & 0.640 & & 0.736 & $<0.001$ & \\
\hline & PU4 & 4.540 & 0.545 & & 0.836 & $<0.001$ & \\
\hline \multirow{4}{*}{ PEOU } & PEOU1 & 4.074 & 0.845 & \multirow{4}{*}{0.650} & 0.722 & $<0.001$ & \multirow{4}{*}{0.881} \\
\hline & PEOU2 & 3.988 & 0.821 & & 0.839 & $<0.001$ & \\
\hline & PEOU3 & 4.103 & 0.724 & & 0.841 & $<0.001$ & \\
\hline & PEOU4 & 4.133 & 0.711 & & 0.818 & $<0.001$ & \\
\hline \multirow{3}{*}{ IQ } & IQ1 & 3.717 & 0.908 & \multirow{3}{*}{0.595} & 0.817 & $<0.001$ & \multirow{3}{*}{0.815} \\
\hline & IQ2 & 3.366 & 1.013 & & 0.789 & $<0.001$ & \\
\hline & IQ3 & 3.906 & 0.879 & & 0.704 & $<0.001$ & \\
\hline \multirow{3}{*}{ BI } & BI1 & 4.404 & 0.570 & \multirow{3}{*}{0.571} & 0.747 & $<0.001$ & \multirow{3}{*}{0.800} \\
\hline & BI2 & 4.407 & 0.595 & & 0.722 & $<0.001$ & \\
\hline & BI3 & 4.174 & 0.694 & & 0.798 & $<0.001$ & \\
\hline
\end{tabular}

Note: $\lambda$ - factor loadings.

gent validity is verified if the indicators used to measure the same latent construct yield strongly correlated scores. For convergent validity to be met, all factor loadings must be significant (Anderson, Gerbing 1988) and larger than 0.5 (Hair et al. 2009). Table 6 shows that all items meet the requirements for convergent validity. Discriminant validity evaluates if the constructs are adequately distinguishable from one another. Discriminant validity is demonstrated if the square root of the AVE of a latent construct is larger than its correlation with any other construct (Fornell, Larcker 1981). Table 7 shows that the measurement model meets the requirement for discriminant validity.

In addition, all fit indices are within the recommended range: $\chi^{2} / d f=1.96, \mathrm{CFI}=0.976, \mathrm{TLI}=0.968, \mathrm{NFI}=0.952$, RMSEA $=0.053$, SRMR $=0.036$ (Byrne 1998; Hu, Bentler 1999; Kline 2015). Thus, the measurement model meets all criteria for reliability and validity and the latent variables can be incorporated into the choice model.

Table 7. Inter-item correlations (square roots of AVE in diagonals)

\begin{tabular}{|l|c|c|c|c|}
\hline Construct & PU & PEOU & IQ & BI \\
\hline PU & 0.750 & & & \\
\hline PEOU & 0.628 & 0.806 & & \\
\hline IQ & 0.567 & 0.699 & 0.771 & \\
\hline BI & 0.637 & 0.676 & 0.645 & 0.756 \\
\hline
\end{tabular}

\subsection{Results of the HCM}

In order to demonstrate the importance of accounting for the causal relationships among latent variables, we also developed a model (HCM_ALL) in which all four latent variables are simultaneously incorporated into the utility function. HCM_TAM corresponds to the model with hierarchical relationships. Though the latent variable and choice models were estimated simultaneously, we display them in separate tables for more clarity. Table 8 shows the results of the choice model and Table 9 shows the results of the structural equations of the latent variables as specified in HCM_TAM. The results of the measurement submodel are shown in Table 10.

In HCM_ALL, only the parameter associated with intention is significant at the $5 \%$ level. The parameter associated with PEOU is significant at $10 \%$, while the two other latent variables have insignificant effects. This shows that IQ, PEOU and PU have little to no direct effect on travellers' route diversion in response to VMS information. However, Table 9 shows that all causal relationships hypothesized in Section 2 are highly significant and have the expected signs. The significant positive effect of IQ on $\mathrm{PU}$ and PEOU supports $\mathrm{H} 4$ and $\mathrm{H} 5$ and is consistent with previous studies (Ahn et al. 2007; Chang et al. 2005). This means that when travellers have a positive perception of IQ, they are likely to develop positive beliefs about the usefulness and ease of use of VMS. The significant and positive effect of PEOU on PU and BI supports $\mathrm{H} 2$ and $\mathrm{H} 3$ and coincides with previous research (Roberts et al. 2012; Xu et al. 2010). This indicates that travellers who believe that VMS information is easy to use are more likely to develop positive beliefs about its usefulness and have higher intention to use it. PU has a positive effect on $\mathrm{BI}$, supporting $\mathrm{H} 1$ and consistent with previous studies (Larue et al. 2015; Park et al. 2015). This means that a salient belief that VMS information is useful increases travellers' intention to use it. Furthermore, BI has a direct and positive effect on route switching behaviour (Table 8), supporting $\mathrm{H} 6$ and indicating that travellers' who have the intention to use VMS information are more likely to divert in response to it. Thus, IQ has a direct and positive effect on PU and PEOU, which have a direct positive effect on 
BI, which, in turn, has a direct and positive effect on route diversion Therefore, even though there is no improvement in terms of model fit, the model accounting for the hierarchical relationships has better explanatory power and is more conform with TAM than the model that directly adds the latent variables into the utility function.
Table 8 also shows the effects of observed attributes on route switching behaviour. The positive sign of the alternative-specific constant shows a certain preference for the expressway. The parameter associated with guidance is negative, indicating that the provision of guidance increases the probability to switch to the local street.

Table 8 . Results of the route choice model

\begin{tabular}{|c|c|c|c|c|}
\hline \multirow{2}{*}{ Variable } & \multicolumn{2}{|c|}{ HCM_ALL } & \multicolumn{2}{|c|}{ HCM_TAM } \\
\hline & estimate & $t$-test & estimate & $t$-test \\
\hline ASC_EXP & 0.409 & 1.92 & 1.99 & 3.82 \\
\hline$\theta \_$GUIDANCE & -0.106 & -5.08 & -0.103 & -5.05 \\
\hline$\theta \_$STOP & -0.362 & -4.66 & -0.351 & -4.63 \\
\hline$\theta \_$TTSAV & -0.308 & -10.72 & -0.306 & -11.26 \\
\hline$\theta$ __INTENTION & 0.534 & 2.24 & 0.321 & 2.26 \\
\hline$\theta$ $\theta$ PERCEIVED_EASE_OF_USE & 0.399 & 1.71 & - & - \\
\hline$\theta$ __PERCEIVED_USEFULNESS & 0.008 & 0.04 & - & - \\
\hline$\theta$ _INFORMATION_QUALITY & 0.358 & 1.34 & - & - \\
\hline$\sigma$ (error component) & 1.69 & 45.36 & 1.85 & 42.01 \\
\hline Number of observations & \multicolumn{2}{|c|}{1356} & \multicolumn{2}{|c|}{1356} \\
\hline Number of draws & \multicolumn{2}{|c|}{1000} & \multicolumn{2}{|c|}{1000} \\
\hline Adjusted $R$-squared & \multicolumn{2}{|c|}{0.602} & \multicolumn{2}{|c|}{0.602} \\
\hline
\end{tabular}

Table 9. Results of the structural part of the latent variable model (based on HCM_TAM)

\begin{tabular}{|c|c|c|c|c|c|c|c|c|}
\hline \multirow{2}{*}{ Variable } & \multicolumn{2}{|c|}{ IQ } & \multicolumn{2}{|c|}{ PEOU } & \multicolumn{2}{|c|}{ PU } & \multicolumn{2}{|c|}{$\mathrm{BI}$} \\
\hline & estimate & $t$-test & estimate & $t$-test & estimate & $t$-test & estimate & $t$-test \\
\hline Intercepts & 1.29 & 5.17 & 1.24 & 2.74 & 1.16 & 3.83 & 0.445 & 1.27 \\
\hline IQ & & & 0.66 & 13.324 & 0.35 & 5.685 & - & - \\
\hline PEOU & & & - & - & 0.433 & 7.164 & 0.373 & 6.683 \\
\hline PU & & & - & - & - & - & 0.521 & 9.044 \\
\hline \multicolumn{9}{|l|}{ Gender (female = reference) } \\
\hline male & 0.133 & 3.82 & 0.176 & 5.5 & 0.123 & 3.3 & 0.259 & 5.41 \\
\hline \multicolumn{9}{|l|}{ Age $($ age $18 \ldots 30=$ reference $)$} \\
\hline $31 \ldots 50$ years old & -0.206 & -2.98 & -0.215 & -4.01 & -0.202 & -3.2 & -0.327 & -3.95 \\
\hline over 50 years old & -0.467 & -3.7 & -0.66 & -6.36 & -0.452 & -3.9 & -0.694 & -4.61 \\
\hline \multicolumn{9}{|c|}{ Income (less than $5000 \mathrm{RMB}=$ reference) } \\
\hline $5000 \ldots 10000 \mathrm{RMB}$ & -0.317 & -3.43 & -0.248 & -5.71 & -0.0548 & -0.93 & -0.116 & -2.03 \\
\hline more than $10000 \mathrm{RMB}$ & -0.419 & -6.32 & -0.351 & -6.1 & -0.229 & -0.425 & -0.192 & -2.37 \\
\hline \multicolumn{9}{|c|}{ Driving years (less than 1 year $=$ reference) } \\
\hline $1 \ldots 5$ years & -0.125 & -2.88 & 0.051 & 1.44 & -0.00227 & -0.06 & -0.101 & -1.83 \\
\hline more than 5 years & -0.331 & -4.94 & 0.232 & 4.31 & -0.0532 & -1.01 & -0.0503 & -0.67 \\
\hline \multicolumn{9}{|c|}{ Route choice style (static $=$ reference) } \\
\hline experience based & 0.113 & 1.22 & 0.165 & 2.18 & -0.127 & -1.56 & 0.0587 & 0.52 \\
\hline information based & 0.464 & 4.8 & 0.514 & 6.16 & 0.235 & 2.95 & 0.613 & 5.52 \\
\hline information-experience based & 0.209 & 2.44 & 0.366 & 5.01 & 0.166 & 2.02 & 0.459 & 4 \\
\hline SD of error terms ${ }^{*}$ & -0.272 & -2.58 & -0.465 & -9.63 & -0.362 & -7.28 & 0.012 & 0.55 \\
\hline
\end{tabular}

Note: in italic - insignificant parameters; ${ }^{\star}$ - the SD is the absolute value of the parameter estimate. 
Table 10. Results of the measurement sub-model

\begin{tabular}{|c|c|c|c|c|c|c|c|}
\hline \multirow{2}{*}{ Construct } & \multirow{2}{*}{ Indicator } & \multicolumn{2}{|c|}{ Intercept } & \multicolumn{2}{|c|}{ Factor loadings } & \multicolumn{2}{|c|}{ Error terms $\sigma$} \\
\hline & & estimate & $t$-test & estimate & $t$-test & estimate & $t$-test \\
\hline \multirow{4}{*}{$\mathrm{PU}$} & PU1 & 0 & - & 1 & - & 1 & - \\
\hline & PU2 & -1 & -4.84 & 1.27 & 15.03 & 0.632 & 14.29 \\
\hline & PU3 & -0.65 & -3.07 & 1.18 & 13.55 & 0.734 & 15.92 \\
\hline & PU4 & -0.088 & -0.5 & 0.974 & 13.21 & 0.43 & 10.68 \\
\hline \multirow{4}{*}{ PEOU } & PEOU1 & 0 & - & 1 & - & 1 & - \\
\hline & PEOU2 & -0.166 & -1.86 & 0.989 & 19.36 & 0.604 & 15.04 \\
\hline & PEOU3 & 0.223 & 2.79 & 0.836 & 18.62 & 0.601 & 17.31 \\
\hline & PEOU4 & 0.289 & 3.68 & 0.841 & 18.93 & 0.536 & 15.16 \\
\hline \multirow{3}{*}{ IQ } & IQ1 & 0 & - & 1 & - & 1 & - \\
\hline & IQ2 & -0.86 & -4.16 & 1.32 & 7.4 & 1.45 & 25.73 \\
\hline & IQ3 & 0.476 & 2.88 & 0.879 & 6.18 & 1.34 & 24.87 \\
\hline \multirow{3}{*}{$\mathrm{BI}$} & BI1 & 0 & - & 1 & - & 1 & - \\
\hline & $\mathrm{BI} 2$ & 0.091 & 0.73 & 0.886 & 16.04 & 0.536 & 13.16 \\
\hline & $\mathrm{BI} 3$ & -0.216 & -1.7 & 0.825 & 15.55 & 0.702 & 17.14 \\
\hline
\end{tabular}

The results also show that as the number of signalized intersections on the local street increases, the propensity to switch decreases. This is similar to findings by Gan and Ye (2012) and shows that even though the travel time on the local street is shorter, the increasing number of signalized intersections may lead the traveller to stay on the expressway. The parameter associated with travel time saving has the expected sign (negative) and shows that as the difference of travel time between expressway and local street increases, the probability to use the alternate route increases as well.

The effects of the individual characteristics are shown in Table 9 along with the causal relationships among latent variables.

For all four latent variables, men have a more positive perception of IQ, a more positive belief about the usefulness and ease of use and a higher intention to use traffic information provided by VMS. This is normal as previous studies have shown that men are more likely to switch in response to VMS information (Jou et al. 2005). The parameters associated with age show that as the age increases, travellers' perception of IQ becomes more negative. Furthermore, older travellers are more likely to have a negative perception of usefulness and ease of use and have a lower intention to use VMS information. This is surprising as previous studies found that older people were more likely to comply with VMS information (Wardman et al. 1997; Zhong et al. 2012). However, this result is consistent with results from Jou et al. (2005) and could be explained by a risk-averse behaviour of older drivers in Dalian, China. The effect of income is surprising as high income was usually associated with higher value of time and higher compliance with ATIS (Li et al. 2015). However, in this study, people with high income have a more negative perception of IQ, are less likely to believe that traffic information is useful and easy to use and have a lower propensity to accept VMS information. Further research is needed in order to understand this finding. Regarding driving experience, as the driving years increase, travellers' beliefs about IQ become less salient, but their perception of ease of use is more positive. This is not surprising as experienced drivers are known for being less dependent on traffic information (Li et al. 2015; Zhong et al. 2012). In terms of route choice style, travellers who use traffic information only have the highest perception about IQ, usefulness and ease of use and the highest probability to comply with ATIS, followed by those who combine traffic information with their own experience.

\section{Conclusions}

This study investigates the effects of travellers' acceptance of VMS on their route switching behaviour. In order to identify the psychological factors affecting the decisionmaking process, we adopted the TAM enriched with IQ as well as observed attributes such as travel time and number of signalized intersections. The obtained HCM was simultaneously estimated using SP data with repeated observations. Several implications can be drawn from the results.

1) TAM can explain travellers' response to VMS if the hierarchical relationships among the different constructs are taken into account;

2) future studies using HCM should consider the hierarchical relationships among latent variables. This approach is more realistic and could help investigate the mediating effect of certain variables on the choice process, especially when some of the latent variables are insignificant, e.g. in research by Vredin Johansson et al. (2006). Perhaps the effects of the insignificant latent variables are mediated by 
the significant ones. The use of a HCM with causal relationships among latent variables could help investigate the mediating effects;

3) the strong positive effect of IQ on PU and PEOU indicates that IQ is a major determinant of travellers' beliefs about VMS. Thus, VMS designers should put more effort into improving the quality of the information provided. This could be done by improving the indicators of IQ, which are accuracy, timeliness and completeness. Regarding completeness, the VMS displayed should be as comprehensive as possible. It should contain enough information to help the traveller make a good decision without too much effort. This will enhance travellers' perception of information quality and as a result, positively affect their perception of usefulness and ease of use. Furthermore, we found that the provision of guidance on the best route also increases the diversion rate. This is due to the fact that the provision of guidance also creates a perception of completeness of the information provided. In addition to guidance, location of incident, cause of incident (congestion, accident, construction, etc.) and information on alternate routes could also be provided. However, ATIS designers should also keep in mind the optimal amount of information that should be displayed as too much information could result in overload and a lower understanding of the information displayed (Richards et al. 2004). Travellers should be able to understand the information without excessive distraction or overload (Dingus, Hulse 1993; Kantowitz 1992). As far timeliness is concerned, the information should be displayed at the right time and right position (not too far from or too close to the detour point). This way, the traveller will have enough time to read the information, process and respond to it in the right manner;

4) the strong positive effect of PU and PEOU on intention indicates that these salient beliefs are the main determinants of travellers' acceptance of VMS. PU has a stronger effect than PEOU, which is consistent with previous studies (Ghazizadeh et al. 2012; Larue et al. 2015) and shows that in voluntary contexts, as in the case of compliance with ATIS, designers should put more emphasis on PU. In case of limited budget, ATIS designers should focus on improving travellers' perception of usefulness. This could be done by organizing campaigns that promote the benefits of ATIS. For example, in case there is no incident to report, the VMS remains blank. During that period, ATIS designers can use it to display how VMS can benefit travellers in their routing decisions. This could help enhance their perception of usefulness. Regarding PEOU, the VMS used in Dalian City only provides the information in a colour-coded format and travellers have to impute the travel time from it. For travellers who are colour blind or do not know the meaning of the road colours, this type of display might be perceived as difficult to use. For example, Richards et al. (2004) used a driving simulator to investigate travellers' comprehension of graphical congestion display panels (GCDP). 60 subjects were chosen and 3 out 4 believed that the colour green was used to indicate the quickest route and was not intended to describe the level of service on the road section. Thus, even though the graphical display is usually preferred, travellers might not understand it (Rämä et al. 2004). Additional text could be used to shortly describe the meaning of each road colour;

5) individual characteristics (age, gender, income, driving experience and route choice style) also affect travellers' perceptions of VMS. However, they do not have a direct effect on the choice behaviour as their impact is absorbed by the latent variables.

However, this study has also some limitations. First, as noted by Chorus and Kroesen (2014), it is difficult to draw policies from HCM with cross-sectional data. In order to evaluate the effectiveness of our recommendations for the improvement of VMS, it is important to investigate drivers' behaviour at different time points. Second, although the results showed that TAM can explain travellers' response to VMS, previous studies have shown that $\mathrm{SP}$ responses do not accurately represent actual behaviour (Chatterjee et al. 2002). Since TAM is intended to predict actual system use, the results would be more accurate if estimated with RP data. The use of a SP method was justified in Section 2. Third, even though the proposed model had better explanatory power, it did not improve the predictive power compared to the traditional HCM. Finally, even though completeness is a requirement for IQ, too much information could also negatively affect travellers' perception of ease of use. In our future studies, we will investigate how the trade-off between completeness and amount of information affects travellers' perception of IQ and ease of use. Despite the aforementioned limitations, by applying TAM to develop a hierarchical HCM, this study brings a unique contribution to our understanding of travellers' acceptance of VMS and the findings could help improve future models using HCM.

\section{Funding}

This work was supported by the National Natural Science Foundation of China under Grant No 51478085.

\section{Author contributions}

El Bachir Diop, Shengchuan Zhao, Shuo Song and Tran Van Duy conceived the study and were responsible for the design and development of the data analysis.

El Bachir Diop, Tran Van Duy and Shuo Song were responsible for data collection and analysis.

El Bachir Diop and Shengchuan Zhao were responsible for data interpretation.

El Bachir Diop wrote the first draft of the article. 


\section{Disclosure statement}

Authors have no conflict of interest to disclose.

\section{References}

Abou-Zeid, M.; Ben-Akiva, M. 2011. The effect of social comparisons on commute well-being, Transportation Research Part A: Policy and Practice 45(4): 345-361. https://doi.org/10.1016/j.tra.2011.01.011

Ahn, T.; Ryu, S.; Han, I. 2007. The impact of Web quality and playfulness on user acceptance of online retailing, Information \& Management 44(3): 263-275. https://doi.org/10.1016/j.im.2006.12.008

Anderson, J. C.; Gerbing, D. W. 1988. Structural equation modeling in practice: a review and recommended two-step approach, Psychological Bulletin 103(3): 411-423. https://doi.org/10.1037/0033-2909.103.3.411

Ayeh, J. K.; Au, N.; Law, R. 2013. Predicting the intention to use consumer-generated media for travel planning, Tourism Management: 132-143.

https://doi.org/10.1016/j.tourman.2012.06.010

Bagozzi, R. P.; Yi, Y. 1988. On the evaluation of structural equation models, Journal of the Academy of Marketing Science 16(1): 74-94. https://doi.org/10.1007/BF02723327

Bekhor, S.; Albert, G. 2014. Accounting for sensation seeking in route choice behavior with travel time information, Transportation Research Part F: Traffic Psychology and Behaviour 22: 39-49. https://doi.org/10.1016/j.trf.2013.10.009

Ben-Akiva, M.; McFadden, D.; Gärling, T.; Gopinath, D.; Walker, J.; Bolduc, D.; Börsch-Supan, A.; Delquié, P.; Larichev, O.; Morikawa, T.; Polydoropoulou, A.; Rao, V. 1999. Extended framework for modeling choice behavior, Marketing Letters 10(3): 187-203. https://doi.org/10.1023/A:1008046730291

Bierlaire, M. 2003. BIOGEME: a free package for the estimation of discrete choice models, in STRC: 3rd Swiss Transport Research Conference, 19-21 March 2003, Ascona, Switzerland, 1-24. Available from Internet:

https://transp-or.epfl.ch/documents/proceedings/Bier03.pdf

Bonsall, P. 1992. The influence of route guidance advice on route choice in urban networks, Transportation 19(1): 1-23. https://doi.org/10.1007/BF01130771

Byrne, B. M. 1998. Structural Equation Modeling with Lisrel, Prelis, and Simplis: Basic Concepts, Applications, and Programming. Lawrence Erlbaum Associates Inc. 432 p.

Cantillo, V.; Arellana, J.; Rolong, M. 2015. Modelling pedestrian crossing behaviour in urban roads: a latent variable approach, Transportation Research Part F: Traffic Psychology and Behaviour 32: 56-67. https://doi.org/10.1016/j.trf.2015.04.008

Chang, I.-C.; Li, Y.-C.; Hung, W.-F.; Hwang, H.-G. 2005. An empirical study on the impact of quality antecedents on tax payers' acceptance of Internet tax-filing systems, Government Information Quarterly 22(3): 389-410.

https://doi.org/10.1016/j.giq.2005.05.002

Chatterjee, K.; Hounsell, N. B.; Firmin, P. E.; Bonsall, P. W. 2002. Driver response to variable message sign information in London, Transportation Research Part C: Emerging Technologies 10(2): $149-169$.

https://doi.org/10.1016/S0968-090X(01)00008-0

Chen, C.-F.; Chen, P.-C. 2011. Applying the TAM to travelers' usage intentions of GPS devices, Expert Systems with Applications 38(5): 6217-6221.

https://doi.org/10.1016/j.eswa.2010.11.047
Chen, H.-H.; Chen, S.-C. 2009. The empirical study of automotive telematics acceptance in Taiwan: comparing three technology acceptance models, International Journal of Mobile Communications 7(1): 50-65. https://doi.org/10.1504/IJMC.2009.021672

Chorus, C. G.; Kroesen, M. 2014. On the (im-)possibility of deriving transport policy implications from hybrid choice models, Transport Policy 36: 217-222. https://doi.org/10.1016/j.tranpol.2014.09.001

Daly, A.; Hess, S.; Patruni, B.; Potoglou, D.; Rohr, C. 2012. Using ordered attitudinal indicators in a latent variable choice model: a study of the impact of security on rail travel behaviour, Transportation 39(2): 267-297. https://doi.org/10.1007/s11116-011-9351-z

Davis, F. D. 1989. Perceived usefulness, perceived ease of use, and user acceptance of information technology, MIS Quarterly 13(3): 319-340. https://doi.org/10.2307/249008

Davis, F. D.; Bagozzi, R. P.; Warshaw, P. R. 1989. User acceptance of computer technology: a comparison of two theoretical models, Management Science 35(8): 982-1003. https://doi.org/10.1287/mnsc.35.8.982

Davis, F. D.; Venkatesh, V. 1996. A critical assessment of potential measurement biases in the technology acceptance model: three experiments, International Journal of Human-Computer Studies 45(1): 19-45. https://doi.org/10.1006/ijhc.1996.0040

Dingus, T. A.; Hulse, M. C. 1993. Some human factors design issues and recommendations for automobile navigation information systems, Transportation Research Part C: Emerging Technologies 1(2): 119-131. https://doi.org/10.1016/0968-090X(93)90009-5

Dutta, A.; Fisher, D. L.; Noyce, D. A. 2004. Use of a driving simulator to evaluate and optimize factors affecting understandability of variable message signs, Transportation Research Part F: Traffic Psychology and Behaviour 7(4-5): 209-227.

https://doi.org/10.1016/j.trf.2004.09.001

Feng, C. M.; Kuo, Y. W. 2007. Comparative analysis of stated enroute switching behavior under various information scenarios, in 2007 International Conference on Wireless Communications, Networking and Mobile Computing, 21-25 September 2007, Shanghai, China, 6150-6153.

https://doi.org/10.1109/WICOM.2007.1508

Fishbein, M.; Ajzen, I. 1975. Belief, Attitude, Intention and Behavior: an Introduction to Theory and Research. Addison-Wesley. $578 \mathrm{p}$.

Fornell, C.; Larcker, D. F. 1981. Evaluating structural equation models with unobservable variables and measurement error, Journal of Marketing Research 18(1): 39-50. https://doi.org/10.2307/3151312

Gan, H.; Ye, X. 2013. Investigation of drivers' diversion responses to urban freeway variable message signs displaying freeway and local street travel times, Transportation Planning and Technology 36(8): 651-668. https://doi.org/10.1080/03081060.2013.851504

Gan, H.; Ye, X. 2012. Urban freeway user' diversion response to variable message sign displaying the travel time of both freeway and local street, IET Intelligent Transport Systems 6(1): 78-86. https://doi.org/10.1049/iet-its.2011.0070

Ghazizadeh, M.; Peng, Y.; Lee, J. D.; Boyle, L. N. 2012. Augmenting the technology acceptance model with trust: commercial drivers' attitudes towards monitoring and feedback, Proceedings of the Human Factors and Ergonomics Society Annual Meeting 56: 2286-2290. https://doi.org/10.1177/1071181312561481

Hair, J. F.; Black, W. C.; Babin, B. J.; Anderson, R. E. 2009. Multivariate Data Analysis. 7th Edition. Pearson. 816 p. 
Hu, L.-T.; Bentler, P. M. 1999. Cutoff criteria for fit indexes in covariance structure analysis: Conventional criteria versus new alternatives, Structural Equation Modeling: a Multidisciplinary Journal 6(1): 1-55.

https://doi.org/10.1080/10705519909540118

Isa, M. H. M.; Deros, B. M.; Kassim, K. A. A. 2015. A review of empirical studies on user acceptance of driver assistance systems, Global Journal of Business and Social Science Review 4(1): 182-189.

Jou, R.-C.; Lam, S.-H.; Liu, Y.-H.; Chen, K.-H. 2005. Route switching behavior on freeways with the provision of different types of real-time traffic information, Transportation Research Part A: Policy and Practice 39(5): 445-461. https://doi.org/10.1016/j.tra.2005.02.004

Kamargianni, M.; Ben-Akiva, M.; Polydoropoulou, A. 2014. Incorporating social interaction into hybrid choice models, Transportation 41(6): 1263-1285.

https://doi.org/10.1007/s11116-014-9550-5

Kantowitz, B. H. 1992. Heavy vehicle driver workload assessment: lessons from aviation, Proceedings of the Human Factors and Ergonomics Society Annual Meeting 36(15): 1113-1117. https://doi.org/10.1518/107118192786749883

Kattan, L.; Nurul Habib, K. M.; Nadeem, S.; Islam, M. T. 2010. Modeling travelers' responses to incident information provided by variable message signs in Calgary, Canada, Transportation Research Record: Journal of the Transportation Research Board 2185: 71-80. https://doi.org/10.3141/2185-10

Kim, J.; Rasouli, S.; Timmermans, H. 2014. Expanding scope of hybrid choice models allowing for mixture of social influences and latent attitudes: application to intended purchase of electric cars, Transportation Research Part A: Policy and Practice 69: 71-85. https://doi.org/10.1016/j.tra.2014.08.016

Kline, R. B. 2015. Principles and Practice of Structural Equation Modeling. 4th Edition. Guilford Press. 534 p.

Koutsopoulos, H.; Polydoropoulou, A.; Ben-Akiva, M. 1993. Public Acceptance and User Response to ATIS Products and Services: the Use of Travel Simulators to Investigate the Response to Traffic Information. US Deptartment of Transportation, Washington, DC, US. 90 p.

Lai, K.-H.; Wong, W.-G. 2000. SP approach toward driver comprehension of message formats on VMS, Journal of Transportation Engineering 126(3): 221-227.

https://doi.org/10.1061/(ASCE)0733-947X(2000)126:3(221)

Larue, G. S.; Rakotonirainy, A.; Haworth, N. L.; Darvell, M. 2015. Assessing driver acceptance of Intelligent Transport Systems in the context of railway level crossings, Transportation Research Part F: Traffic Psychology and Behaviour 30: 1-13. https://doi.org/10.1016/j.trf.2015.02.003

Levinson, D. 2003. The value of advanced traveler information systems for route choice, Transportation Research Part C: Emerging Technologies 11(1): 75-87.

https://doi.org/10.1016/S0968-090X(02)00023-2

Li, X.; Cao, Y.; Zhao, X.; Xie, D. 2015. Drivers' diversion from expressway under real traffic condition information shown on variable message signs, KSCE Journal of Civil Engineering 19(7): 2262-2270. https://doi.org/10.1007/s12205-014-0692-y

Lin, T.-W.; Lin, C.-Y.; Hsu, W.-H. 2014. Effects of system characteristics on adopting web-based advanced traveller information system: evidence from Taiwan, Promet - Traffic \& Transportation 26(1): 53-63. https://doi.org/10.7307/ptt.v26i1.1224

Ma, Z.; Shao, C.; Song, Y.; Chen, J. 2014. Driver response to information provided by variable message signs in Beijing, Transportation Research Part F: Traffic Psychology and Behaviour 26: 199-209. https://doi.org/10.1016/j.trf.2014.07.006
Majumder, J.; Kattan, L.; Nurul Habib, K.; Fung, T. S. 2013. Modelling traveller response to variable message sign, International Journal of Urban Sciences 17(2): 259-280.

https://doi.org/10.1080/12265934.2013.776288

Mariel, P.; Meyerhoff, J. 2016. Hybrid discrete choice models: Gained insights versus increasing effort, Science of The Total Environment 568: 433-443.

https://doi.org/10.1016/j.scitotenv.2016.06.019

NBSC. 2016. China Statistical Yearbook. National Bureau of Statistics of China (NBSC), China Statistics Press. Available from Internet: http://www.stats.gov.cn/tjsj/ndsj/2016/indexeh.htm

Park, E.; Kim, H.; Ohm, J. Y. 2015. Understanding driver adoption of car navigation systems using the extended technology acceptance model, Behaviour \& Information Technology 34(7): 741-751. https://doi.org/10.1080/0144929X.2014.963672

Paulssen, M.; Temme, D.; Vij, A.; Walker, J. L. 2014. Values, attitudes and travel behavior: a hierarchical latent variable mixed logit model of travel mode choice, Transportation 41(4): 873888. https://doi.org/10.1007/s11116-013-9504-3

Peeta, S.; Ramos, J. L. 2006. Driver response to variable message signs-based traffic information, IEE Proceedings - Intelligent Transport Systems 153(1): 2-10.

https://doi.org/10.1049/ip-its:20055012

Prato, C. G.; Bekhor, S.; Pronello, C. 2012. Latent variables and route choice behavior, Transportation 39(2): 299-319. https://doi.org/10.1007/s11116-011-9344-y

Rämä, P.; Schirokoff, A.; Luoma, J. 2004. Potential harmonisation of variable message signs in Viking countries, Nordic Road and Transport Research 16(3): 4-5.

Richards, A.; Mcdonald, M.; Fisher, G.; Brackstone, M. 2004. Investigation of driver comprehension of traffic information on graphical congestion display panels using a driving simulator, European Journal of Transport and Infrastructure Research 4(4): 417-435. https://doi.org/10.18757/ejtir.2004.4.4.4276

Roberts, S. C.; Ghazizadeh, M.; Lee, J. D. 2012. Warn me now or inform me later: drivers' acceptance of real-time and postdrive distraction mitigation systems, International Journal of Human-Computer Studies 70(12): 967-979.

https://doi.org/10.1016/j.ijhcs.2012.08.002

Shah, V. P.; Wunderlich, K.; Toppen, A.; Larkin, J. 2003. Potential of advanced traveler information system to reduce travel disutility: assessment in Washington, D.C., region, Transportation Research Record: Journal of the Transportation Research Board 1826: 7-15. https://doi.org/10.3141/1826-02

Toledo, T.; Beinhaker, R. 2006. Evaluation of the potential benefits of advanced traveler information systems, Journal of Intelligent Transportation Systems: Technology, Planning, and Operations 10(4): 173-183. https://doi.org/10.1080/15472450600981033

Venkatesh, V. 2000. Determinants of perceived ease of use: integrating control, intrinsic motivation, and emotion into the technology acceptance model, Information Systems Research 11(4): 342-365. https://doi.org/10.1287/isre.11.4.342.11872

Venkatesh, V.; Davis, F. D. 2000. A theoretical extension of the technology acceptance model: four longitudinal field studies, Management Science 46(2): 186-204.

https://doi.org/10.1287/mnsc.46.2.186.11926

Venkatesh, V.; Morris, M. G.; Davis, G. B.; Davis, F. D. 2003. User acceptance of information technology: toward a unified view, MIS Quarterly 27(3): 425-478. https://doi.org/10.2307/30036540

Vredin Johansson, M.; Heldt, T.; Johansson, P. 2006. The effects of attitudes and personality traits on mode choice, Transportation Research Part A: Policy and Practice 40(6): 507-525. https://doi.org/10.1016/j.tra.2005.09.001 
Wardman, M.; Bonsall, P. W.; Shires, J. D. 1997. Driver response to variable message signs: a stated preference investigation, Transportation Research Part C: Emerging Technologies 5(6): 389-405. https://doi.org/10.1016/S0968-090X(98)00004-7

Xu, C.; Wang, W.; Chen, J.; Wang, W.; Yang, C.; Li, Z. 2010. Analyzing travelers' intention to accept travel information: structural equation modeling, Transportation Research Record: Journal of the Transportation Research Board 2156: 93-100. https://doi.org/10.3141/2156-11

Yáñez, M. F.; Raveau, S.; Ortúzar, J. de D. 2010. Inclusion of latent variables in mixed logit models: modelling and forecasting, Transportation Research Part A: Policy and Practice 44(9): 744-753. https://doi.org/10.1016/j.tra.2010.07.007

Zhong, S.; Zhou, L.; Ma, S.; Jia, N. 2012. Effects of different factors on drivers' guidance compliance behaviors under road condition information shown on VMS, Transportation Research Part A: Policy and Practice 46(9): 1490-1505.

https://doi.org/10.1016/j.tra.2012.05.022 